\title{
Música e vozes em Pickpocket (1959), de Robert Bresson ${ }^{1}$
}

\author{
Luíza Alvim
}

Resumo: O cineasta francês Robert Bresson ficou conhecido pelo uso criativo dos diversos elementos sonoros em seus filmes e pela parcimônia na inserção de música. Em obras da fase intermediária de sua carreira, como Um condenado à morte escapou (1956), Pickpocket (1959) e A grande testemunha (1966), peças pré-existentes do repertório clássico foram utilizadas como música extradiegética e possuem aspectos formais que guardam analogias com sua distribuição nos respectivos filmes. Além disso, em Pickpocket, a música pré-existente de Lully também se relaciona com as vozes in e over. Na maioria das vezes, a voz in do final dos diálogos desencadeia os trechos de música, colocados em situações de movimento e com uma função semelhante ao divertimento na ópera barroca. Consideramos também as relações entre voz in e over e defasagens desta última com a ação e a imagem do diário do protagonista sendo escrito.

Palavras-chave: Robert Bresson; música no cinema; voz over; voz in; análise fílmica; análise musical.

Abstract: Music and voices in Pickpocket (1951), by Robert Bresson - The French director Robert Bresson was known for his creative use of sound elements and the scanty insertion of music in his films. In films produced during the intermediary phase of his career, such as $A$ man escaped (1956), Pickpocket (1959) and Au hasard Balthazar (1966), preexisting classical music pieces, which contain formal aspects that are analogous to their distribution in the respective films, were used as non-diegetic music. Moreover, in Pickpocket, the preexisting music by Lully also relates to the voice-in and voice-over. The voice-in at the end of the dialogues usually triggers musical excerpts, which are inserted in situations of movement and whose function resembles that of divertissements in baroque opera. We also consider the relations between voice-in and voice-over and the lag between the latter and the action and the image of the main character's diary as it is being written.

Keywords: Robert Bresson; music in cinema; voice over; voice in; filmic analysis; musical analysis.

1 Trabalho apresentado no XVII Encontro da SOCINE, no Seminário Temático de Estudos do Som, em outubro de 2013. 


\section{Introdução}

O cineasta francês Robert Bresson ficou conhecido pelo uso criativo do som em seus filmes, sendo um exemplo disso as vozes dos intérpretes: estes foram, a partir do terceiro longa-metragem, Diário de um padre (1951), convocados entre não-atores e chamados pelo diretor de "modelos". Além disso, foi observado, em nossa tese de doutorado, que a música, embora empregada com bastante parcimônia na maior parte dos filmes de Bresson, era um elemento fundamental de sua composição de sons e imagens (ALVIM, 2013a).

Pickpocket (1959) é o quinto longa-metragem do diretor. É a história do estudante Michel, que se torna batedor de carteiras, mas, já na prisão, acaba se redimindo por meio do amor de Jeanne, a vizinha de sua mãe. Muitos autores, entre os quais nos incluímos, viram no filme uma adaptação livre do romance Crime e castigo, de Dostoievski, embora, no livro, o crime seja de assassinato e não de furto.

Pickpocket é o segundo filme em que Bresson utiliza quase que somente música do repertório clássico pré-existente e de forma extradiegética - a primeira vez em que havia procedido assim foi com o uso exclusivo e econômico do Kyrie da Missa em dó menor de Mozart no longa-metragem anterior, Um condenado à morte escapou (1956) e é o terceiro em que faz uso de voz over ${ }^{2}$ no sentido clássico de um personagem contando uma história, como nos anteriores Diário de um padre e Um condenado à morte escapou 3 . Além disso, em Diário de um padre e Pickpocket, os protagonistas escrevem um diário: a imagem dessa escrita é mostrada e tem relação tanto com a voz over quanto com a música.

No tocante à música extradiegética em Pickpocket, os extratos são todos provenientes da Suíte $n .7$ em sol menor do compositor barroco Jean-Baptiste Lully. Além de possuírem aspectos formais relevantes como um todo, estão intimamente associados à voz over, considerada por Miranda (2008) como mais uma inserção musical neste filme.

Tal fato já acontecia, de certa forma, nos dois filmes anteriores. Mas, em Pickpocket, Bresson acrescenta uma relação com a voz in dos diálogos: é ela que desencadeia quase todos os trechos de música.

Tal expediente já tinha sido empregado no último momento de música em Um condenado à morte escapou: tendo conseguido fugir da prisão, o companheiro do protagonista lhe diz: "Si ma mère me voyait" ("Se minha mãe me visse"4), o que desencadeia o trecho final do Kyrie de Mozart. É como um prenúncio do procedimento básico "voz seguida de música" de Pickpocket.

\section{A música de Lully em Pickpocket}

Lully era, na verdade, italiano (nos créditos de Pickpocket, encontramos, inclusive, a grafia italiana de seu nome, Lulli), mas foi o compositor oficial do rei Luís XIV

2 Preferimos utilizar a nomenclatura voz over da tradição anglófona no lugar de voz off.

3 Em filmes da última fase da carreira do diretor, como Uma mulher suave (1969) e Quatro noites de um sonhador (1972), a voz over volta em formas diferentes. Para saber mais, ver ALVIM, 2013 a.

4 Todas as traduções das citações em francês são de nossa autoria. 
e o criador da ópera barroca francesa. Já a suíte é uma peça musical constituída por uma série de danças, muito comum no período barroco. Por exemplo, a suíte n.7, presente em Pickpocket, contém uma introdução - dividida numa parte de andamento lento e outra mais viva (Allegro) -, um minueto, uma passacalha (passacaille, em francês, ou, em sua designação mais comum, em italiano, passacaglia: dança de origem espanhola e andamento relativamente rápido, em compasso ternário) e uma bourrée. Mas os extratos presentes no filme são oriundos apenas da introdução e da passacalha.

Provavelmente, a suíte como tal não é originalmente de Lully. Era comum, no Barroco, compositores fazerem suítes a partir de óperas e balés de outros. No caso, a passacalha de Pickpocket vem do quinto ato da ópera Armide ${ }^{5}$, de Lully. Na partitura, publicada pelas Éditions Musicales Transtlantiques, vemos a indicação de que houve uma "reconstituição" por Fernand Oubradous, compositor do século XX que costumava fazer arranjos de peças barrocas.

Segundo Jardonnet e Chabrol (2005), o conjunto das cenas de roubo de Pickpocket é semelhante à estrutura tripartita lento-rápido-lento ( $\mathrm{ABA}^{\prime}$ ) da abertura da ópera francesa ${ }^{6}$. Ou seja, no início e no final do filme, Michel executa os seus roubos sozinhos no hipódromo de Longchamps e há uma lentidão também na decupagem ( $\mathrm{A}$ e $\mathrm{A}^{\prime}$ ). No meio do filme (B), ele tem a ajuda de vários comparsas, havendo mais movimento.

Num filme posterior de Bresson, A grande testemunha (1966), também com música extradiegética pré-existente do repertório clássico (no caso, trechos do Andantino da Sonata para piano D959 de Schubert), demonstramos (ALVIM, 2013a, 2013b) uma analogia entre a distribuição dos extratos musicais no filme e a estrutura musical da peça original (no caso, com formas musicais da sonata).

Tanto nesse longa-metragem, como em Um condenado à morte escapou, muito importante é o uso da repetição de trechos ao longo do filme (ALVIM, 2012, 2013a, 2013b). O próprio Bresson afirma, a respeito deste aspecto: "Todos esses efeitos que você pode obter da repetição (de uma imagem, de um som)" (BRESSON, 2008, p.49, grifo do autor).

Já em Pickpocket, só há duas repetições de trechos (os que nomeamos de "tema musical" A e $A^{\prime}$, e B e $B^{\prime}$ ) e, mesmo assim não completas (daí Áe B' ao invés de simplesmente $\mathrm{A}$ e $\mathrm{B}$ ), como podemos ver na tabela 1, a seguir.

No entanto, a repetição ocorre também pela utilização da passacalha, dança de onde vêm a maior parte dos trechos, já que ela é caracterizada por uma estrutura musical de repetição e variação a partir de um baixo em ostinato ${ }^{7}$ (SILBIGER, 1996). Como

5 Armide é uma ópera de 1686, com libretto de Philippe Quinault, baseado no poema épico Jerusalém libertada de Torquato Tasso. Ambientada durante a Primeira Cruzada, é a história da paixão conflituosa da feiticeira Armida pelo guerreiro Renaud (Rinaldo). No site da Criterion, responsável pelo DVD americano do filme, está indicado, erradamente, que a música viria da ópera Atys, também de Lully.

6 A estrutura da abertura francesa é o contrário da abertura italiana, rápido-lento-rápido, que se manteve posteriormente na forma geral dos movimentos de concertos e sinfonias.

7 O ostinato é um motivo ou frase musical que se repete persistentemente na mesma voz (no caso da passacalha, o baixo). 
veremos mais adiante, trechos da passacalha também estão relacionados entre si no filme. Por exemplo, extratos são associados ora à Jeanne (tema C da tabela 1) e sua tentativa de tirar Michel do caminho do crime, ora à tentação do roubo (tema D), representando o conflito de sentimentos do protagonista.

\begin{tabular}{|c|c|c|c|c|c|}
\hline Trecho & Tempo no filme & $\begin{array}{l}\text { Tema } \\
\text { musical }\end{array}$ & Parte na partitura & Compassos & No filme \\
\hline 1 & $0^{\circ}-152^{\prime \prime}$ & A & $\begin{array}{l}\text { Parte lenta da } \\
\text { introdução }\end{array}$ & $\begin{array}{l}1-16 \text { (com a } \\
\text { repetiçầo) }\end{array}$ & Créditos \\
\hline 2 & $2257-23.44 \cdots$ & B & Passacalha & $81-105$ & $\begin{array}{l}\text { Michel aprende os truques } \\
\text { com o comparsa }\end{array}$ \\
\hline 3 & $28^{\prime} 56^{\prime \prime}-29^{\prime} 11^{\prime \prime}$ & C & Passacalha & $1-9$ & $\begin{array}{l}\text { No final do diálogo com } \\
\text { Jeanne, apos o enterro da } \\
\text { mà̃e }\end{array}$ \\
\hline 4 & $44^{\prime} 53^{\prime}-45^{\prime} 09^{\prime \prime}$ & D & Passacalha & $33-41$ & $\begin{array}{l}\text { Após o diálogo com Jacques } \\
\text { e o roubo do relogio }\end{array}$ \\
\hline 5 & $5605^{\circ}-56^{\prime} 38^{\prime \prime}$ & $\mathrm{B}^{-}$ & Passacalha & $81-97$ & $\begin{array}{l}\text { Apos o dialogo como } \\
\text { delegado }\end{array}$ \\
\hline 6 & $59^{\prime} 45^{\prime \prime}-61^{\prime} 27^{\prime \prime}$ & $E$ & $\begin{array}{l}\text { Allegro da } \\
\text { introdução }\end{array}$ & $\begin{array}{l}17-36(\text { com a } \\
\text { repetiçâa) + 31-36 }\end{array}$ & $\begin{array}{l}\text { No final do diálogo com } \\
\text { Jeanne. Ele vai para a } \\
\text { estaçấ. }\end{array}$ \\
\hline 7 & $6236^{\prime \prime}-63^{\prime} 01^{\prime \prime}$ & F & Passacalha & $\begin{array}{l}9 \text { (depois de final } \\
\text { de C) }-21\end{array}$ & $\begin{array}{l}\text { Michel chega a Paris, após } \\
\text { dois anos }\end{array}$ \\
\hline 8 & $65222^{\prime \prime}-66^{\prime} 14^{\prime \prime}$ & $\mathrm{A}^{-}$ & $\begin{array}{l}\text { Parte lenta da } \\
\text { intro duçäo }\end{array}$ & $\begin{array}{l}\text { 1-16 (sem a } \\
\text { repetiçâo) }\end{array}$ & $\begin{array}{l}\text { Michel tenta trabalhar } \\
\text { honestamente. }\end{array}$ \\
\hline 9 & $73^{\prime} 53^{\prime \prime}-7533^{\prime \prime}$ & $\begin{array}{l}C-F^{\prime}-G- \\
D-B^{*}-H\end{array}$ & Passacalha & $\begin{array}{l}1-13+57-65+ \\
33-41+89-105 \\
+113-121\end{array}$ & $\begin{array}{l}\text { Michel e Jeanne se beijam } \\
\text { por entre as grades da prisão }\end{array}$ \\
\hline
\end{tabular}

Tab.1. Trechos de música em Pickpocket, com os temas musicais associados, sua proveniência e o momento do filme em que se encontram. Em rosa, os trechos lentos ( $\mathrm{A} \mathrm{e} \mathrm{A}^{\prime}$ ); em amarelo, os trechos de andamento mais rápido, entre os dois lentos; em fundo branco, o último trecho, com vários extratos da passacalha.

De uma maneira geral, percebemos que dois trechos lentos $\left(A\right.$ e $A^{\prime}$, retirados da parte lenta da introdução) envolvem trechos rápidos $\left(B, B^{\prime}, C, D, E, F\right.$, retirados do Allegro da introdução e da passacalha), tal como acontece na abertura francesa (tabela 1). Além disso, A e Á introduzem ambas as sequências do hipódromo no início e no final do filme: o uso do mesmo tema musical as aproxima, como observam Jardonnet e Chabrol (2005).

Mais ainda, há outro eco do final do filme em relação ao seu início: a palavra chemin (caminho) contida no texto explicativo da abertura - "cette aventure, par des chemins étranges, réunira deux âmes" ("esta aventura, por estranhos caminhos, reunirá duas almas") - e na voz over de Michel, durante o último trecho musical do filme : O Jeanne, pour aller jusquà toi, quel drôle de chemin il máa fallu prendre! ("Oh, Jeanne, para ir até você, que caminho curioso eu tive que tomar!"). Já vemos, nesses dois momentos, uma relação entre voz over, elementos escritos do filme e música.

Em relação ao último trecho de música de Pickpocket (n. 9, da tabela 1), com extratos só da passacalha, podemos dizer que ele funciona como a retomada de outros momentos do filme, um pouco como acontecia nas óperas da Lully, em que o final contava com o canto e dança de todos os personagens. 
No caso específico de Armide, de onde vem a passacalha, é interessante que essa dança ocorre após o único dueto de amor da ópera (entre a personagem título e o cavaleiro Renaud), do mesmo modo que, no filme, o trecho 9 é o momento onde o amor de Michel e Jeanne se torna declarado.

Na versão da passacalha da ópera de Lully, em meio à dança, tal qual a voz over de Michel (de caráter musical, como observado por Miranda, 2008) durante o trecho de música no filme, um solista canta "Les plaisirs ont choisi pour asile / Ce séjour agreáble et tranquille" ("Os prazeres escolheram como refúgio / Este lugar agradável e tranquilo"), e, na estrofe seguinte, "C'est l'amour qui retient dans ses chaînes / mille oiseaux [...]" ("É o amor que retem em suas correntes / mil pássaros [...]"). Curioso observar que, no filme, o "lugar agradável" é uma prisão, ao passo em que há uma referência a ela na letra da ópera pelas "correntes" (no caso do libretto, a prisão metafórica do amor; já, no filme, é uma prisão literal).

Podemos perceber outras analogias, se levarmos em conta que a maior parte dos trechos do filme vem da passacalha: assim, também é possível associar o seu contínuo retorno em Pickpocket com o caráter circular da dança (SILBIGER, 1996) ${ }^{8}$.

Outra coisa interessante quanto à ópera francesa de Lully é o fato de terem os recitativos um caráter mais falado que cantado, além de que as emoções das árias eram mais comedidas em relação ao "canto mais animado" da ópera italiana, na definição de um músico do século XVII, André Maugars (apud COELHO, 1999). Portanto, a ópera francesa tinha mais sobriedade e contenção. Isso lembra a própria contenção da expressividade por parte dos "modelos" de Bresson, que nos dão a impressão de falarem como se lessem um texto.

Numa visão do século XVIII sobre a ópera de Lully, em comparação ao estilo mais novo de Rameau, Diderot (1996), em seu livro O sobrinho de Rameau, coloca na boca de um personagem a afirmação de que Rameau os teria livrado do "cantochão de Lulli". A palavra "cantochão" está empregada aí de forma pejorativa e no sentido de música monótona, adjetivo utilizado por muitos críticos para caracterizar negativamente as falas nos filmes de Bresson.

\section{Música e movimento}

Os momentos de música no filme são também aqueles em que Michel se desloca no espaço. São, portanto, situações de movimento, função pretendida pelo próprio Bresson (em entrevista a François Weyergans, em $1965^{9}$ ) para a música neste filme.

Segundo Danielle Dahan (2004), a música teria, em Pickpocket, uma função de divertimento pascaliano, estando presente "sempre que Michel foge da 'realidade' após um evento que o reconduziria à finitude da existência ou o exortaria a uma confrontação

8 Agradecemos a Nelson Pinton Filho por esta lembrança.

9 "A música aprofunda [...], coloca-nos numa espécie de ambiência própria para receber certas coisas. [...] Em Pickpocket, [...] a música trazia um movimento" (tradução nossa a partir da entrevista de Bresson em francês, feita por Weyergans). 
com a existência levada por ele"10 (DAHAN, 2004, p.126). Com efeito, para Pascal, o divertimento é o que afasta o homem da reflexão, só possível no repouso.

Mas podemos também associar a música em Pickpocket a um dos significados do divertimento barroco nas óperas de Lully: canções, coros e danças que formavam uma cena separada na ópera e produziam uma quebra na ação ${ }^{11}$. No caso da passacalha presente no filme, ela é um divertimento da ópera Armide.

Assim, em Pickpocket, os trechos musicais são ouvidos, além dos créditos, em momentos de transição (caso da volta de Michel a Paris, após dois anos no exterior), ou no final de conversas tensas de Michel com Jeanne, Jacques ou com o delegado, como se fossem os divertimentos após as árias e duetos de Armide.

Dahan (2004) observa que a música começa após um acontecimento ou uma palavra, que desencadearão em Michel o sentimento da necessidade de fuga. Com efeito, dos nove momentos de música de Pickpocket, em sete deles, observamos uma relação direta com a fala, seja over ou in.

Refizemos, então, a tabela 1, acrescentando as "frases desencadeadoras" da música (tabela 2, a seguir).

A associação com o movimento da dança é bem evidente na famosa sequência, nomeada por diversos críticos como "o ballet das mãos", em que, com a frase "Venez voir" ("Venha ver"), o comparsa mais experiente convida Michel e o espectador a assistirem a uma performance (há mesmo um silenciamento da banda sonora antes do início da música), momento em que o protagonista aprende os truques do métier num salão de bar (trecho 2, com tema B).

É como se a passacalha de Lully fosse aí a música de fosso (na classificação de Chion (1995), música de fosso e de tela correspondem, respectivamente, a música extradiegética e diegética; a nomenclatura de Chion faz lembrar a posição da orquestra no fosso do palco). Aliás, poderíamos dizer que os movimentos das mãos dos batedores de carteiras possuem a elegância das danças do século dezessete.

10 No original: "dès que Michel fuit la 'réalitéaprès un événement qui soir le ramènerait à la finitude de l'existence soit l'acculerait à une confrontation avec l'existence quill mène".

11 Sobre o divertimento, há vários artigos na enciclopédia Grove e também o verbete de Bouissou (1996). 


\begin{tabular}{|c|c|c|c|c|}
\hline Trecho & $\begin{array}{l}\text { Tema } \\
\text { musical }\end{array}$ & Parte na partitura & Compassos & $\begin{array}{l}\text { Frase desencadeadora ou relação com o texto } \\
\text { escrito }\end{array}$ \\
\hline 1 & A & $\begin{array}{l}\text { Parte lenta da } \\
\text { introdução }\end{array}$ & $\begin{array}{l}1-16(\operatorname{com} a \\
\text { repetiçâo) }\end{array}$ & Creditos: texto de apresentação \\
\hline 2 & B & Passacalha & $81-105$ & $\begin{array}{l}\text { Voz in do comparsa: para Michel "Venha } \\
\text { ver" }\end{array}$ \\
\hline 3 & $c$ & Passacalha & $1-9$ & $\begin{array}{l}\text { Voz in de Michel respondento a Jeanne: "Eu } \\
\text { cri em Deus por três minutos". }\end{array}$ \\
\hline 4 & $D$ & Passacalha & $33-41$ & $\begin{array}{l}\text { Voz over de Michel, apos diálogo com } \\
\text { Jacques: "O relogio era muito bonito" }\end{array}$ \\
\hline 5 & $\mathrm{~B}^{\prime}$ & Passacalha & $81-97$ & $\begin{array}{l}\text { Voz in de Michel para o delegado: "Eu quero } \\
\text { conhecé-las!" }\end{array}$ \\
\hline 6 & $E$ & $\begin{array}{l}\text { Allegro da } \\
\text { introdução }\end{array}$ & $\begin{array}{l}17-36(\operatorname{com} a \\
\text { repetiçầo })+31-36\end{array}$ & $\begin{array}{l}\text { Voz in de Michel, respondendo a Jeanne: } \\
\text { "Nâo, não" }\end{array}$ \\
\hline 7 & $F$ & Passacalha & $\begin{array}{l}9 \text { (depois de final } \\
\text { de C) }-21\end{array}$ & $\begin{array}{l}\text { Texto escrito do diário lido pela voz over de } \\
\text { Michel }\end{array}$ \\
\hline 8 & $A^{\prime}$ & $\begin{array}{l}\text { Parte lenta da } \\
\text { introdução }\end{array}$ & $\begin{array}{l}1-16 \text { (sem a } \\
\text { repetiçầo) }\end{array}$ & $\begin{array}{l}\text { Voz in de Michel para Jeanne: "Deixe-me ao } \\
\text { menos tentar" - com retardo da entrada da } \\
\text { musica }\end{array}$ \\
\hline 9 & $\begin{array}{l}C-F^{\prime}-G- \\
D-B^{\prime}-H\end{array}$ & Passacalha & $\begin{array}{l}1-13+57-65+ \\
33-41+89-105 \\
+113-121\end{array}$ & $\begin{array}{l}\text { Voz over de Michel: "Alguma coisa iluminou } \\
\text { o seu rosto"). }\end{array}$ \\
\hline
\end{tabular}

Tab. 2. Em laranja, os trechos de música desencados pela voz in; em azul, os desencadeados pela voz over; em lilás, os que têm relação somente com textos escritos (o texto de apresentação em 1 e o diário de Michel em 7).

Esta aproximação é reforçada, como observou Dahan (2004), pelo fato de que a palavra "graça" (essencial na obra de Pascal, também do século XVII) seja pronunciada pelo comentário over de Michel durante a música: "Il me les donna sans hésiter, et de la meilleure grâce du monde" ("Ele [o pickpocket] me ensinou [os truques] sem hesitar, e com a melhor graça do mundo").

\section{Voz in, música e movimento}

Em Pickpocket, como podemos ver na tabela 2, em cinco dos nove momentos, a música irrompe ao final de algum diálogo, em geral, bruscamente interrompido: sua frase final desencadeia a música. Bernard (1963) considera que, ao se relacionar dessa forma com a palavra, a música prolonga a ressonância afetiva do diálogo como um todo, dilatando o espaço e o tempo no momento em que a ouvimos.

Por outro lado, Giorgio Tinazzi (1976) constata que a música não intervém para marcar o momento culminante (por exemplo, o de uma revelação), como normalmente se esperaria no seu uso corriqueiro no cinema: ela irrompe assim que os diálogos (e, principalmente, o seu clímax) já se foram.

Nesse filme, os diálogos são travados como batalhas por Michel, tendo, como oponentes, o amigo Jacques, Jeanne e o delegado que o investiga. Daí a importância de suas últimas frases, que revelam sentimentos distintos de Michel de acordo com o interlocutor. 
Geralmente, ele corta os diálogos com Jacques de forma súbita e autoritária, é evasivo com Jeanne, mas, diante do delegado, um adversário mais forte, deixa-se tomar pela raiva.

Durante a música que se segue às frases finais, há sempre um movimento (e aí, lembremos do divertimento, tanto no sentido pascaliano quanto no da ópera de Lully), um deslocamento no espaço.

Nos diálogos com Jacques, associados ao corte autoritário de Michel, não ouvimos música, ou, quando isso acontece, é um tempo depois do diálogo, não é a sua última frase que a desencadeia. Assim, após o roubo do relógio, Michel é bastante mordaz com o amigo, cortando a conversa, indagando-lhe sobre o amor dele por Jeanne e sugerindo-Ihe ironicamente, "comprar-lhe presentes".

Mas o trecho 4 (com extrato musical D, da passacalha) só irromperá depois da saída de Jacques e é desencadeado pelo comentário over de Michel, "La montre était très belle" ("O relógio era muito bonito"). Há, então, um deslocamento com elipse - temos: a saída de Michel, a imagem do diário e o término da música no plano em que o protagonista chega à Gare de Lyon para praticar o roubo conjunto com os comparsas.

Jeanne é um adversário mais forte. Embora, na maior parte do tempo, Michel esteja na posição de comando das questões, a moça, por vezes, consegue tomar a frente. Por exemplo, com a sua indagação, no diálogo após a morte da mãe do protagonista, "Vous ne croyez à rien?" ("O senhor não crê em nada?"): a hesitação no meio da resposta, "Jáai cru en Dieu [pausa], pendant trois minutes" ("Eu cri em Deus, por três minutos"), mostra o momento de respiro de Michel após o golpe recebido. Logo depois disso, começa a música (trecho 3, tema musical C, também da passacalha, de estrutura semelhante a D).

Como no trecho musical $\mathrm{D}$, em $\mathrm{C}$ há também um deslocamento de Michel para um lugar de roubo. Da mesma maneira, vemos a seguinte sequência de ações e imagens: ele sai, aparece a imagem do seu diário e o término da música ocorre no plano do banco onde o rapaz tentará um golpe junto com seus comparsas.

Os movimentos e imagens semelhantes em C e D reforçam a ligação entre esses dois momentos, já presente em suas estruturas musicais parecidas.

Também as conclusões dos diálogos de Michel com Jeanne são menos em corte seco (como no caso daqueles com Jacques), e mais no sentido da evasiva, com respostas que, por vezes, querem dizer exatamente o seu contrário. Assim, no último diálogo com a moça antes da fuga, à pergunta "Vous allez partir?" ("O senhor vai partir?"), Michel diz "Non, non" ("Não, não"), fazendo, a seguir, exatamente o contrário. Aí, irrompe a música (trecho 6, tema B, proveniente do Allegro).

Há também, nesse momento, uma relação das vozes in com a voz over de Michel, pois, entre a pergunta de Jeanne (sobre a sua partida) e a sua resposta (negando), ouvimos o seu comentário over, que, justamente, considera a possibilidade evocada por Jeanne (e que vai acabar sendo a ação do personagem durante a música). Essas relações entre 
voz in - voz over e música mostram numa permeabilidade entre espaços extradiegético e diegético, semelhante ao que foi analisado quanto à música por Robynn Stilwell (2007)12.

Em relação à música em si, o Allegro é o trecho de andamento mais rápido do filme. Na imagem, há também uma grande agitação: Michel se dirige apressadamente à estação de trem. A música indica também todo o movimento que vai acontecer a seguir, quase que uma pirueta de dança, pois o protagonista pega um trem para Milão.

Na volta de Michel a Paris, em outro diálogo com Jeanne, há um certo retardo do desencadeamento da música pela fala de Michel, "Laisse-moi au moins essayer" "Deixe-me ao menos tentar"). A seguir, durante a música, vemos imagens da tentativa do protagonista de ajudar Jeanne e seu bebê com o dinheiro de um emprego honesto: há um deslocamento no espaço e uma função comum à música de cinema de recobrir a passagem do tempo.

O tema musical é o mesmo dos créditos e é por isso que, mais do que associá-lo à suposta regeneração de Michel, Jardonnet e Chabrol (2005) enfatizam a aproximação entre as duas sequências do hipódromo. Com efeito, (A`) está antes do encontro de Michel, num bar, com o policial disfarçado de apostador, fato que o levará de volta às pistas de corrida de cavalos.

Finalmente, o delegado é o oponente mais perigoso de Michel. Como lembra Collet (1960), é o único interlocutor capaz de provocar um acesso de raiva no protagonista, que, mesmo fugaz, é uma exteriorização de sua grande tensão. O delegado chega até a manipular parte do diálogo, assumindo a posição de "narrador" de uma história (JARDONNET; CHABROL, 2005): "Une plainte avait été déposée il y a plus d'un an..." ("Uma queixa foi feita há mais de um ano..."). Desta vez, é ele que interrompe o diálogo com o seu silêncio e a sua saída brusca após a injunção de Michel "Je veux les connaître" ("Quero conhecer [as intenções do policial]").

A fala de Michel também desencadeia nesse momento a música (trecho 5 - extrato $\mathrm{B}^{\prime}$ da passacaille) e há um deslocamento elíptico durante ela, que termina no plano de Jeanne abrindo a porta, numa fusão de espaços (quarto de Michel - casa de Jeanne).

Em relação à música em si deste momento, vemos que, por ser a metade de $\mathrm{B}$, que ocorrera durante o "ballet das mãos" no café, é como se fosse uma recapitulação desse trecho, evocada pela presença do delegado e por suas insinuações quanto aos roubos de Michel.

\section{Voz over: imagens do diário e música}

A voz over de Michel pontua todo o filme. Porém, além do trecho D já evocado, apenas outro trecho musical é desencadeado por ela: o último do filme, que se passa na prisão, quando Michel recebe a visita de Jeanne e sua voz over diz: "Quelque chose illumina sa figure" ("Algo iluminou o seu rosto").

12 Em seu artigo, Stilwell (2007) dá vários exemplos de como o que nos parece música extradiegética é, por vezes, mostrado, num plano seguinte, como pertencente à diegese. Do mesmo modo, é também comum que músicas justificadas na diegese continuem em sequências seguintes como extradiegéticas. Em ambas as situações, a música atravessa o "fantástico intervalo" entre os espaços diegético e extradiegético. 
Por outro lado, é importante também observar que, em quatro momentos, a voz over se associa à imagem do diário escrito pelo protagonista: o início do filme (após os créditos e o tema A), durante o tema C, durante o tema D e quando Michel chega à Gare de Lyon após dois anos foragido (trecho 7, tema F). A voz over e a imagem do diário estão junto com a música em todos estes momentos, com exceção da primeira sequência do filme, após os créditos.

Aliás, junto com a música dos créditos (tema $A$ ), o tema $F$ é o único que não é desencadeado por nenhuma frase específica, sendo ouvido sobre a imagem do diário, que é lido pela voz over de Michel. Este aspecto distinto marca também o fato de se constituir na única elipse temporal grande do filme (dois anos). Por outro lado, o trecho se assemelha aos momentos de voz over junto com imagens da palavra já escrita, em Diário de um padre.

Em relação a este filme, Bazin (1991) notava que a voz over, que lê o escrito no diário, não seria uma simples redundância com o visível, "o som nunca está aqui para completar o acontecimento visto: ele reforça e multiplica como a caixa de ressonância do violino o faz com as vibraçoes das cordas." (ibidem, 1991, p.119).

Bazin complementa que o percebido seria, mais que uma ressonância, "uma defasagem como a de uma cor não superposta ao desenho" (BAZIN, 1991, p.119). A palavra "defasagem" nos parece bastante apropriada para explicar as pequenas diferenças de sincronia entre fala, escrita e ação ${ }^{13}$. Por exemplo, em Um condenado à morte escapou, Bresson explorou bastante as defasagens entre o que era dito pela voz over e a ação mostrada: às vezes, a descrição da voz precede a imagem, outras vezes, é o contrário.

Em Diário de um padre e em Pickpocket, este aspecto da defasagem se torna mais complexo pela introdução de um terceiro elemento: a imagem do diário. Desta forma, nesses filmes, além dos dois planos temporais da voz over e da imagem, há também as defasagens entre o que é dito pelo comentário over e o que está sendo (ou já foi) escrito no diário.

Em Diário de um padre, na maioria das vezes, começamos a ouvir a voz do padre sobre a imagem da escrita já avançada (há também, por vezes, linhas já escritas que não são lidas), mas, a voz está, em geral, num andamento mais rápido que o da escrita, alcançando-a e, normalmente, ultrapassando-a (primeiro e segundo caso do esquema 1). São também os casos, em Pickpocket, da primeira sequência após os créditos e da leitura da imagem do diário durante os temas C e D de música.

Já em quatro momentos de Diário de um padre, ouvimos só o comentário sobre o rosto do padre, mas logo, ao vermos a imagem do caderno, observamos que ele já havia escrito o comentado (terceiro caso do esquema 1). Há também dois momentos em que

13 A fase e a defasagem foram bastante empregadas na música minimalista de Steve Reich. Por exemplo, em diversas peças do compositor, como em Piano phase (1967), dois instrumentos (no caso, dois pianos) começam a tocar a mesma melodia em sincronia. A seguir, um deles faz uma pequena desaceleração ou aceleração, conferindo uma diferença de "fase". Em outra versão recente de Piano phase, Reich empregou o vídeo, associando a imagem pré-gravada de um baterista tocando em defasagem com o mesmo baterista em performance ao vivo (Piano - Video Phase, 2002). 
a imagem da escrita desaparece antes do término da fala (quarto caso). Em Pickpocket, há uma mistura desses dois modos justamente na grande elipse temporal do filme (durante o tema musical F): a imagem nos mostra o diário já escrito sendo lido pelo protagonista e o fade da imagem ocorre antes que a voz acabe de ler as linhas.

Desta maneira, constatamos que, longe de uma simples redundância, a voz over e a imagem do caderno estão como em dois planos separados.

\section{Escrita (imagem do \\ diário já escrito) \\ Fala}

\section{Escrita (imagem do diário já escrito)}

Fala

\section{Escrita \\ Fala}

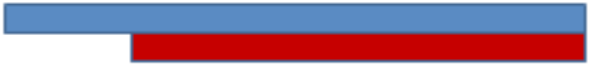

Escrita

Fala

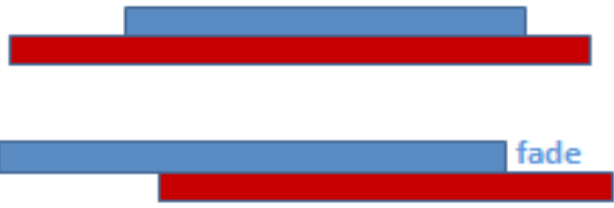

Esquema 1. Tipos de relações entre imagem do diário escrito e da voz over em Diário de um padre.

Diferentemente do que acontece em Um condenado à morte escapou, a voz over de Michel tem um caráter de defasagem menos marcado, estando, muitas vezes, quase que simultaneamente sobre as imagens descritas (caso, por exemplo, do momento da sua primeira captura, após o furto inicial no hipódromo), ou ainda, servindo para marcar elipses e adiantar a narrativa (como, por exemplo, quando ele diz, após o furto no metrô: "Jáavais pris soin de varier les parcours, voyageant tantôt sur une ligne, tantôt sur une autre"14). Quando há alguma defasagem voz-imagem, a voz está muito pouco antes da imagem.

Na verdade, em Pickpocket, essa defasagem, que tanto dá ritmo a Um condenado à morte escapou e a Diário de um padre, é menos empregada em prol da relação voz over - voz in: é como se o comentário de Michel dialogasse com os fatos e conversas, demonstrando a fluidez da separação entre espaços diegético e extradiegético.

\section{Conclusão}

Em Pickpocket, a maneira parcimoniosa com que a música extradiegética é utilizada mostra analogias entre a obra de origem (as peças de Lully, rearranjadas por Oubradous) e a distribuição dos trechos no filme, assim como são essenciais as suas relações com

14 "Tomei o cuidado de variar os percursos, andando às vezes numa linha, outras vezes, em outra". 
outros elementos sonoros: as vozes in e over. Como se interpelados por elas, os trechos de música são desencadeados, na maior parte das vezes, por uma frase e se dão em momentos de movimentação, semelhante às danças, aos divertimentos de Lully.

Sendo o último filme de Bresson em que ouvimos comentários over do protagonista juntamente com imagens do processo da escrita de um diário, em Pickpocket, as defasagens entre voz, imagem do diário e ação são menos importantes que nos filmes anteriores. Muito mais ritmo a este filme conferem as relações voz in - voz over e o desencadear da música pela voz, esta mesma funcionando como uma inserção musical.

Luíza Alvim é doutora em Comunicação e Cultura pela UFRJ e pós-doutoranda em Música pela Universidade Federal do Estado do Rio de Janeiro (UNIRIO).

luizabeatriz@yahoo.com

\section{Referências}

ALVIM, Luíza. Simetrias, repetições e variações - Analogias de Um condenado à morte escapou com a Missa em dó menor de Mozart. Avanca Cinema, 2012.

. Robert Bresson e a música. Tese de doutorado apresentada ao Programa de Pós-Graduação em Comunicação da Universidade Federal do Rio de Janeiro, 2013a.

. A sonata de Bresson. Galáxia, n.25, jun. 2013b.

BAZIN, André. O Cinema: Ensaios. São Paulo: Brasiliense, 1991.

BERNARD, Renée. Pickpocket - Fiche Filmographique IDHEC, 1963.

BOUISSOU, Sylvie. Vocabulaire de la musique baroque. Minerve, 1996.

BRESSON, Robert. Notas sobre o cinematógrafo. São Paulo: Iluminuras, 2008.

CHION, Michel. La musique au cinéma. Paris: Fayard,1995.

COELHO, Lauro Machado. A ópera na França - História da ópera. São Paulo: Perspectiva, 1999.

COLLET, Jean. Pickpocket, Fiche n.363. Téléciné, n.88, mars $₫$ avril, 1960.

DAHAN, Danielle. Robert Bresson: une téléologie du silence. Heidelberg: Universitätsverlag Winter, 2004.

DIDEROT, Denis. Le neveu de Rameau. Pocket, 1996.

JARDONNET, Évélyne; CHABROL, Marguerite. Pickpocket de Robert Bresson. Neuilly: Atlande, 2005.

MIRANDA, Suzana Reck. Duas vozes para o som no cinema: Tati e Bresson. In: ADES, Eduardo et al (org.). O som no cinema. Caixa Cultural, 2008, p. 30-35.

SILBIGER, Alexander. Passacaglia and Ciaccona: Genre Pairing and Ambiguity from Frescobaldi to Couperin. Journal of Seventeenth Century Music, v.2, n.1, 1996. 
STILWELL, Robynn. The fantastical gap between diegetic and nondiegetic. In: GOLDMARK, Daniel; KRAMER, Lawrence; LEPPERT, Richard (org.). Beyond the soundtrack: representing music in cinema. Los Angeles: University of California Press, 2007.

TINAZZI, Giorgio. Il cinema di Robert Bresson. Venezia: Marsilio Editori, 1976.

www.oxfordmusiconline.com : site com artigos da enciclopédia Oxford e da versão eletrônica da enciclopédia de música Grove.

\section{Partitura}

LULLY, Jean-Baptiste. Suíte n.7 em sol menor (reconstituição: Fernand Oubradous), Éditions Musicales Transatlantiques.

\section{Referências audiovisuais (em ordem cronológica)}

DIÁRIO DE UM PADRE (Journal d'un curé de campagne), Robert Bresson, França, 1951.

UM CONDENADO À MORTE ESCAPOU (Un condamné à mort s'est échappé ou le vent souffle où il veut), Robert Bresson, França, 1956.

PICKPOCKET - o batedor de carteiras (Pickpocket), Robert Bresson, França, 1959.

A GRANDE TESTEMUNHA (Au hasard Balthazar), Robert Bresson, França / Suécia, 1966.

UMA MULHER SUAVE (Une femme douce), Robert Bresson, França, 1969.

QUATRO NOITES DE UM SONHADOR (Quatre nuits d'un rêveur), Robert Bresson, França / Itália, 1972.

BRESSON NI VU NI CONNU, François Weyergans, França, 1994. Contém entrevista de Bresson, realizada em 1965. 